\title{
Resolution Control in a Continuous Preferential Crystallization Process
}

\author{
Andrew S. Dunn, ${ }^{\dagger, \S(1) ~ V a c l a v ~ S v o b o d a, ~}{ }^{\dagger, \| \oplus \text { Jan Sefcik, }}{ }^{+, \|}$and Joop H. ter Horst ${ }^{*},+, \S_{(0)}$ \\ ${ }^{\dagger}$ EPSRC Doctoral Training Centre in Continuous Manufacturing and Crystallisation Embedded in the Future Manufacturing Hub \\ for Continuous Manufacture and Advanced Crystallisation (CMAC), Technology and Innovation Centre, University of Strathclyde, \\ 99 George Street, Glasgow G1 1RD, U.K. \\ ${ }^{\ddagger}$ EPSRC Future Manufacturing Hub for Continuous Manufacture and Advanced Crystallisation (CMAC), Technology and \\ Innovation Centre, University of Strathclyde, 99 George Street, Glasgow G1 1RD, U.K. \\ ${ }^{\S}$ Strathclyde Institute of Pharmacy and Biomedical Sciences (SIPBS), 161 Cathedral Street, Glasgow G4 0RE, U.K. \\ "Department of Chemical and Process Engineering, University of Strathclyde, James Weir Building, 75 Montrose Street, Glasgow \\ G1 1XJ, U.K.
}

Supporting Information

ABSTRACT: Preferential crystallization is a technique used to separate enantiomers and is usually performed in batch mode. For a continuously operated preferential crystallization process from a supersaturated racemic solution, however, nucleation and growth of the unwanted counter enantiomer eventually becomes inevitable, and a controlling measure should be taken. Through the use of polarimetry as an effective monitoring tool to detect the crystallization of the unwanted enantiomer, a novel strategy to eliminate the unwanted enantiomer crystals in a continuous cooling preferential crystallization process is presented. The strategy involves switching from the racemic feed solution to an enantiopure feed solution upon detection of the counter enantiomer crystals. This allows selective dissolution of the counter enantiomer crystals while the preferred enantiomer crystals continue to crystallize. After all of the counter enantiomer crystals are dissolved by decreasing the counter enantiomer solution concentration sufficiently below its solubility, the feed is switched back to the racemic solution. Through the use of this modelfree controlling action the continuous process does not have to be terminated. Instead, this method rectifies the situation to the initial metastable steady state by using a portion of the produced enantiomer product. The process can therefore operate at higher supersaturations compared with existing processes for longer periods of time since the control action does not rely on the dissolution kinetics of the system but rather on the thermodynamics of the phase diagram. We show that this new approach is an effective and scalable control strategy for achieving enantiopure product in a continuous preferential crystallization process.

KEYWORDS: chiral resolution, continuous crystallization, preferential crystallization, polarimetry, model-free control

\section{INTRODUCTION}

If a molecule has a nonsuperimposable mirror image, it is termed chiral. ${ }^{1}$ The importance of chiral molecules in the pharmaceutical industry became clear during the 1960s when thalidomide was used as a treatment for morning sickness during pregnancy. ${ }^{2}$ Another example is ibuprofen, which is administered in racemic form, although only the $S$ enantiomer is reported to have a therapeutic effect. ${ }^{3}$ Drug regulatory agencies have now enforced that both enantiomers of an active pharmaceutical ingredient (API) must be tested and that, if necessary, only the active enantiomer should be marketed. ${ }^{4}$ It is therefore important to be able to separate enantiomers efficiently and effectively.

Crystallization-based resolution techniques such as Viedma ripening $^{5-8}$ and preferential crystallization ${ }^{9-15}$ (PC) are very efficient because of the highly enantioselective crystalline phase. In a PC process, by seeding of a racemic or enantiomerically enriched solution with crystals of the preferred pure enantiomer, control over the crystallizing enantiomer is obtained. This process can be applied for resolution only if the racemic mixture of enantiomers in the solution forms a conglomerate system in the solid phase, ${ }^{12}$ i.e., a racemic mixture of enantiopure crystals. ${ }^{1}$ A racemic solution of the amino acid asparagine in water, for instance, forms a conglomerate of asparagine monohydrate crystals. ${ }^{16}$

However, PC processes can only run for a limited period of time because nucleation of the counter enantiomer in the supersaturated solution becomes increasingly likely with process time. ${ }^{17,18}$ There are control strategies using coupled batch PC processes that significantly reduce the risk of unwanted primary nucleation of the counter enantiomer by decreasing its supersaturation through exchange of solution between coupled crystallizers. ${ }^{19,20}$ Continuous processes have many advantages over batch processes, including higher throughput ${ }^{18}$ and greater reproducibility ${ }^{21}$ as well as reduced $\operatorname{costs}^{22}$ and a reduction in the number of process steps. ${ }^{23,24}$ The pharmaceutical industry is therefore becoming increasingly interested in introducing continuous crystallization in its manufacturing. ${ }^{25-27}$ A continuous PC process in a continuously stirred crystallizer with feed and suspension outflow operates in a metastable steady state in which only the

Received: June 18, 2019

Published: August 12, 2019 
preferred enantiomer is crystallized while the counter enantiomer remains dissolved in the supersaturated solution. $^{28,29}$ Thus, the counter enantiomer crystals will eventually crystallize and contaminate the product from the continuous PC.

Here we aim to define a novel control strategy to eliminate the counter enantiomer crystals upon their detection in a continuous PC process. The conglomerate system of DLasparagine monohydrate (DL-asn) in water was used as a model compound. Since polarimetry has been shown previously to be a useful monitoring tool for PC processes, ${ }^{11,13,29,30}$ first a monitoring technique based on this was verified using PC in batch. For enantiopure systems, polarimetry can give concentration information, and for enantiomerically enriched systems, it can give an accurate determination of the enantiomeric excess in the solution and therefore, through mass balance, the enantiomeric excess in the crystalline phase. ${ }^{31}$ Then an attempt was carried out to dissolve any particles of D-asn that spontaneously nucleated by raising the temperature within the vessel of a batch PC. Finally, a continuous PC process was carried out using an effective control strategy based on temporarily switching the feed stream from a racemic solution to an enantiopure solution in order to undersaturate D-asn, leading to complete dissolution of this form in the crystallizer.

\section{EXPERIMENTAL SECTION}

2.1. Materials and Methods. DL-Asparagine monohydrate (DL-asn) and L-asparagine monohydrate (L-asn) were purchased from Sigma-Aldrich (Germany). Seed crystals of L-asn were prepared through subsequent sieving to obtain a sieve fraction of $180-250 \mu \mathrm{m}$. Deionized water, purified using a Milli-Q gradient system from Milipore SAS (France), was used as a solvent.

Optical rotation analysis was conducted using an AUTOPOL IV polarimeter (Rudolph Research Analytical, UK) with a $100 \mathrm{~mm}$ optical rotation cell. Solid-free solution was continuously removed from the crystallizer via a sintered glass filter ( $250 \mathrm{~mm} \times 13 \mathrm{~mm}$; ROBU Glasfilter, Germany) of pore size $10-20 \mu \mathrm{m}$ (porosity 4 ) and pumped through the polarimeter cell by a Watson-Marlow (UK) $520 \mathrm{DU}$ peristaltic pump at a flow rate of $45 \mathrm{~mL} / \mathrm{min}$. Under these conditions, the solution from the reactor required $20 \mathrm{~s}$ to reach the polarimeter to be measured. Optical rotation measurements were recorded every $10 \mathrm{~s}$, and each measurement was obtained at $30{ }^{\circ} \mathrm{C}$ and a wavelength of $436 \mathrm{~nm}$. The path length of the polarimeter cell was $100 \mathrm{~mm}$. Points that deviated significantly from the observed trend (e.g., because of bubbles in the sample line) were removed from the data. Nucleation of D-asn caused fluctuations in the optical rotation, as some crystals of D-asn most likely blocked the sintered filter. To remedy the blockage, the filter was replaced with a clean one. This meant that no optical rotation reading was available for approximately $2 \mathrm{~min}$ during the change.

Gravimetric analysis was conducted to determine the total solution concentration. For this, a slurry sample was filtered, and a known amount of the filtrate was added to a preweighed vial and left to evaporate. The ratio of the remaining mass to the evaporated solvent volume is the overall concentration of the chiral compound.

Chiral HPLC analysis was carried out using an Agilent HPLC instrument to determine the enantiomeric excess of the solution and recovered solid product. Solid samples obtained from the filtered slurry were dissolved in water at a concentration of $1 \mathrm{mg} / \mathrm{mL}$ of solvent. A CHIROBIOTIC $\mathrm{T}$ column (Astec, $150 \mathrm{~mm} \times 4.6 \mathrm{~mm}$ with a particle size of 5 $\mu \mathrm{m})$ was used at $25.0{ }^{\circ} \mathrm{C}$ with a $70: 30 \mathrm{v} / \mathrm{v}$ methanol/water mobile phase (flow rate of $0.5 \mathrm{~mL} / \mathrm{min}$ ) and $\mathrm{UV}$ detection at $205 \mathrm{~nm}$. The injection volume was $5 \mu \mathrm{L}$.

2.2. Solubility and Metastable Zone Width Measurements. Solubility measurements were carried out using a Crystal16 crystallization system (Technobis, The Netherlands). L-asn samples of increasing concentration from 5 to $85 \mathrm{mg} / \mathrm{mL}$ of $\mathrm{H}_{2} \mathrm{O}$ in increments of $5 \mathrm{mg} / \mathrm{mL}$ were made up in $1 \mathrm{~mL}$ Crystal16 vials. The temperature profile was set to run from 5 to $55^{\circ} \mathrm{C}$ at a heating rate of $0.3{ }^{\circ} \mathrm{C} / \mathrm{min}$, and then the temperature was held at $55^{\circ} \mathrm{C}$ for $30 \mathrm{~min}$. The temperature was then reduced back to $5{ }^{\circ} \mathrm{C}$ at a cooling rate of $-0.3{ }^{\circ} \mathrm{C}$ / min and held there for $30 \mathrm{~min}$. The cycle was repeated three times. The stirring rate was set to $700 \mathrm{rpm}$. The Crystal16 system uses turbidity to measure the clear point (the temperature point at which no more crystals are present in solution) and the cloud point (the temperature at which crystals first appear in suspension). The difference between the clear and cloud point temperatures gives the metastable zone width (MSZW). For vials whose contents crystallized during the $30 \mathrm{~min}$ hold at $5{ }^{\circ} \mathrm{C}$, the cloud point was discarded.

2.3. Batch Seeded PC. 2.3.1. Experimental Setup. The experimental setup, shown in Figure 1, consisted of a jacketed

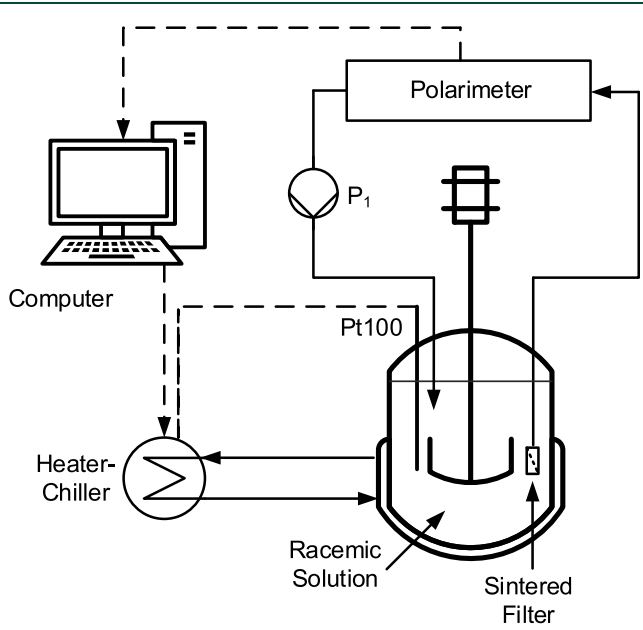

Figure 1. Batch crystallization setup for the temperature control strategy. The enantiomeric excess $E$ in solution is measured continuously via the polarimeter loop. The measured optical rotation is logged by the computer, which also controls the set-point temperature of the heater-chiller.

stirred tank reactor (STR) (Radleys, UK) with a working volume of $500 \mathrm{~mL}$. The temperature in the vessel was controlled by a PT-100 temperature sensor connected to a Lauda Eco630 (Germany) heater-chiller. Solid-free solution was continuously pumped from the vessel via the sintered glass filter through the polarimeter and recycled back via a peristaltic pump $\left(\mathrm{P}_{1}\right)$. The filter was prone to blocking, particularly during primary nucleation events. However, quickly changing the filter proved to be the simplest and most effective workaround. The polarimeter was connected to a computer to log optical rotation measurements. This computer was also connected to the heater-chiller in order to monitor and control the temperature within the vessel. 


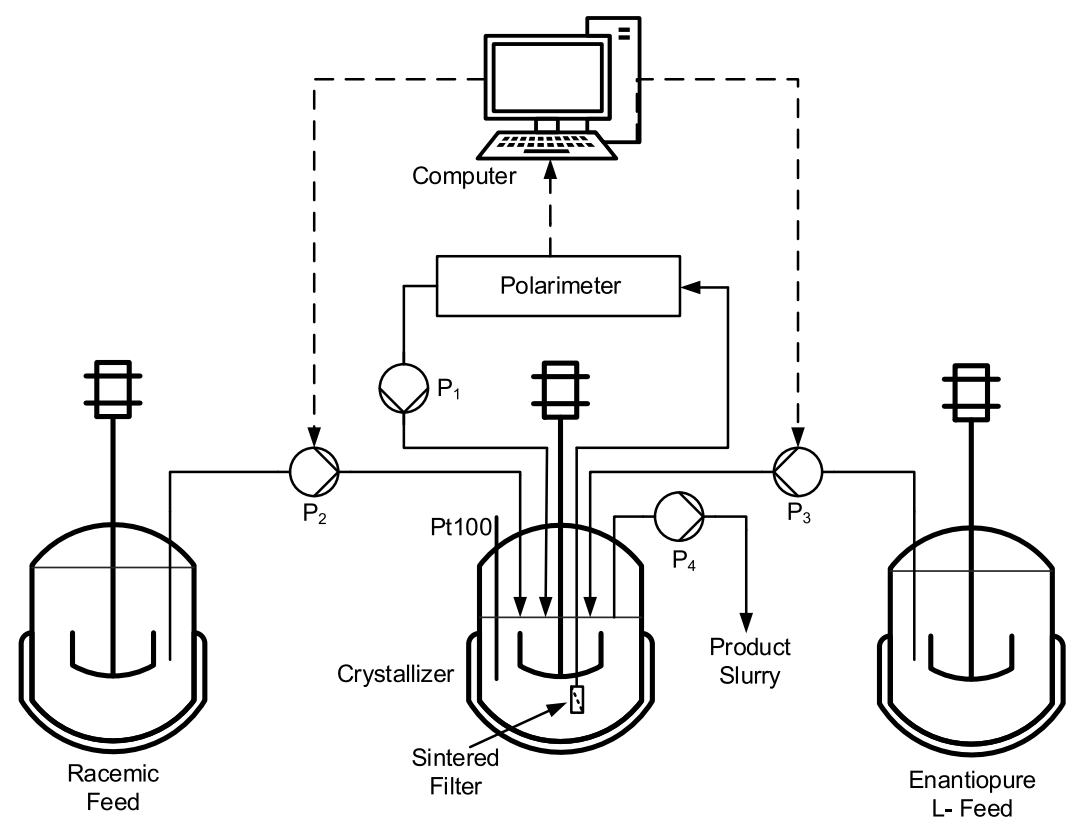

Figure 2. Continuous crystallization setup for the concentration control strategy. A second enantiopure feed tank is used for process control; only one feed tank is active at any one time. The feed tank that is active depends on the optical rotation trend, which is continuously measured by the polarimeter.

2.3.2. Experimental Procedure. DL-asn was added to water in the vessel such that an overall composition of $78 \mathrm{mg} / \mathrm{mL}$ of solvent was obtained. The vessel was heated to $10{ }^{\circ} \mathrm{C}$ above the saturation temperature $\left(T_{\text {sat }}=32.0^{\circ} \mathrm{C}\right)$ until all of the solid was dissolved and a clear solution was obtained. Once a clear solution was obtained, the set-point temperature was changed to the crystallization temperature $\left(T_{\mathrm{cr}}=25.0^{\circ} \mathrm{C}\right)$, generating a supersaturation ratio $(S)$ of 1.3. As soon as $T_{\text {cr }}$ was reached, 0.6 $\mathrm{g}$ of L-asn seeds was added to the vessel to grow under isothermal conditions.

Upon the detection of D-asn crystal formation, given by a decrease in the optical rotation value with time, the set-point temperature $\left(T_{\mathrm{sp}}\right)$ was increased to $13{ }^{\circ} \mathrm{C}$ above the saturation temperature of both enantiomers (i.e., $45.0{ }^{\circ} \mathrm{C}$ ) to rapidly increase the temperature within the vessel. Just before $T_{\text {sat }}$ was reached, $T_{\mathrm{sp}}$ was decreased back to $T_{\mathrm{cr}}$. When D-asn crystallizes, the solution composition tends toward a racemic composition, decreasing the total asn concentration, and hence, the optical rotation value decreases toward $0^{\circ}$. Therefore, a decrease in the optical rotation value can be used to detect D-asn crystal formation.

2.4. Concentration Control Approach for Continuous PC. 2.4.1. Experimental Setup. For the concentration control approach, a continuous setup was used, as depicted in Figure 2. The crystallization vessel used was the same one as described in section 2.3.1, but it was employed as a mixed suspension mixed product removal (MSMPR) vessel with the polarimeter connected in the same way. This time, however, the crystallizer had a working volume of $250 \mathrm{~mL}$. Two feed vessels were used: a $5 \mathrm{~L}$ racemic solution feed vessel and a $1 \mathrm{~L}$ enantiopure solution feed vessel. Only one of these vessels continuously fed saturated solution to the crystallizer at any one time, while the product slurry was continuously removed from the crystallizer. The temperature in the racemic feed vessel was controlled using a Lauda Alpha heater-chiller, and the temperature in the enantiopure feed vessel was controlled using a Lauda Eco630 heater-chiller. The flow from each feed vessel was delivered by a Watson-Marlow 520 DU peristaltic pump. The product slurry was continuously removed by a Masterflex (USA) L/S peristaltic pump.

2.4.2. Experimental Procedure. The racemic feed vessel was charged with a solution of DL-asn at a concentration of $87 \mathrm{mg} /$ $\mathrm{mL}$ of solvent $\left(T_{\text {sat }}=35.0{ }^{\circ} \mathrm{C}\right)$. The $1 \mathrm{~L}$ enantiopure feed vessel was charged with an enantiopure solution of $\mathrm{L}$-asn having a concentration equal to the L-asn concentration in the racemic solution (i.e., $43.5 \mathrm{mg} / \mathrm{mL}$ of solvent). Once the crystallizer cooled to $T_{\mathrm{cr}}=25.0^{\circ} \mathrm{C}$, giving a supersaturation ratio of $S=1.45$, the polarimeter loop pump $\mathrm{P}_{1}$ was started, giving an initial optical rotation value of $0.000^{\circ}$. Soon after, $2 \mathrm{~g}$ of $\mathrm{L}$-asn seeds was added, and $\mathrm{P}_{2}$ and $\mathrm{P}_{4}$ were started. The inlet pumps from the feed vessels $\left(\mathrm{P}_{2}\right.$ and $\left.\mathrm{P}_{3}\right)$ were calibrated to deliver a flow rate of $4.17 \mathrm{~g} / \mathrm{min}$, giving a residence time of 60 min in the crystallizer (the pump from the enantiopure feed $\mathrm{P}_{3}$ was on standby until nucleation of D-asn occurred). The outlet of the crystallizer was level-controlled by pump $\mathrm{P}_{4}$. Steady state in the system was determined when the optical rotation value obtained remained constant (to within $\pm 0.003^{\circ}$ ).

Upon the appearance of D-asn crystals, as indicated by a decrease in the optical rotation value from the steady-state value determined by the polarimeter, pump $\mathrm{P}_{2}$ was stopped and pump $\mathrm{P}_{3}$ was started. The target concentration of D-asn is predetermined on the basis of the ternary phase diagram (see Figure 6), but a target supersaturation ratio of $S_{\mathrm{D}}=0.9$ was used in order to ensure that all of the D-asn dissolved while the supersaturation ratio for L-asn was maintained.

The time period $t$ during which the feed solution was switched, assuming perfect mixing, is given by

$$
t=\tau \ln \left(\frac{C_{0}}{C_{\mathrm{t}}}\right)
$$

where $\tau$ is the residence time in the crystallizer, $C_{0}$ is the starting concentration of D-asn in the crystallizer, and $C_{\mathrm{t}}$ is the target final concentration of D-asn (see the Supporting Information for the derivation). After time $t$, the final 
concentration was reached, the enantiopure feed solution $\mathrm{P}_{3}$ was stopped, and the racemic feed solution $\mathrm{P}_{2}$ was restarted. Slurry samples and subsequent solid and liquid samples were taken at various points during the process (see section 3.3) for concentration and enantiomeric excess determination.

\section{RESULTS}

3.1. Solubility and Metastable Zone Width. The solubility and MSZW of asparagine monohydrate are shown in Figure 3. Each experimental point shown is the average clear

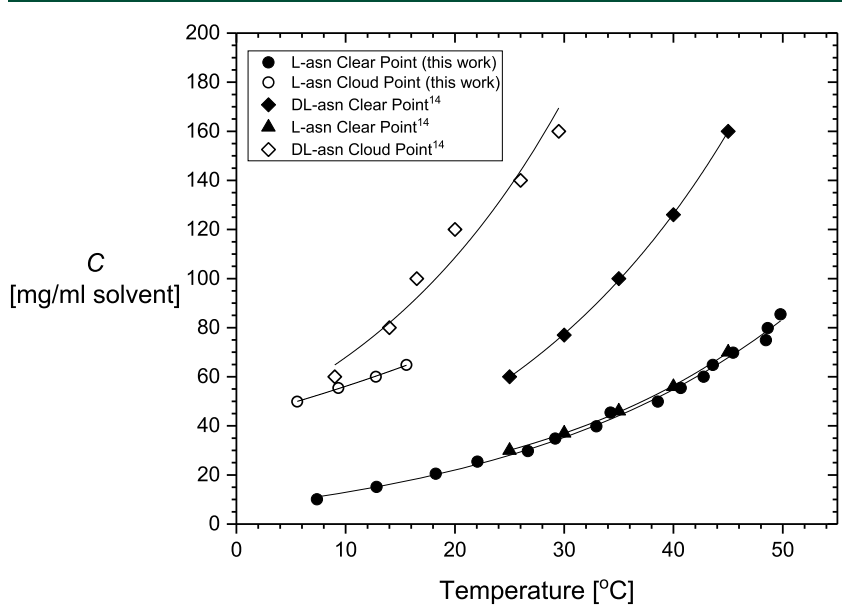

Figure 3. Experimental and reference solubility data for L-asn and DLasn: (O) experimental L-asn solubility curve determined in this work; $(\mathrm{O})$ experimental L-asn cloud point determined in this work; $(\diamond)$ solubility of DL-asn monohydrate, $(\boldsymbol{\Lambda})$ solubility of enantiopure L-asn, and $(\diamond)$ cloud point of racemic DL-asn monohydrate, as determined by Kongsamai et al. ${ }^{14}$ All concentrations of asparagine are based on the monohydrate solid form.

point (solid squares) or cloud point (square rings) over three measurements of a single sample, and the variations in the clear and cloud points obtained were not larger than the symbols. At a temperature of $25{ }^{\circ} \mathrm{C}$, the solubility of DL-asparagine monohydrate is $60.0 \mathrm{mg}$ of $\mathrm{DL}-\mathrm{asn} / \mathrm{mL}$ of water, while that of L-asparagine monohydrate is $29.9 \mathrm{mg} / \mathrm{mL}$. Since the solubility of L-asn is half that of DL-asn, this shows that for this conglomerate system the solubility of L-asn is not significantly affected by the presence of an equal amount of D-asn at $25.0{ }^{\circ} \mathrm{C} .{ }^{14}$ This measured solubility compares well to literature values. ${ }^{14,32,33}$ Furthermore, the measured MSZW of L-asn is substantial, approximately $18{ }^{\circ} \mathrm{C}$ between clear and cloud points, although it varies by approximately $2{ }^{\circ} \mathrm{C}$ across different concentrations.

3.2. Batch Seeded PC. It is possible to preferentially crystallize L-asn monohydrate under well-controlled conditions, ${ }^{13,14}$ for instance, through batchwise seeded preferential crystallization of L-asn from a $78.0 \mathrm{mg} / \mathrm{mL}$ racemic aqueous solution of DL-asn monohydrate. Such a solution is saturated at a temperature of $32.0{ }^{\circ} \mathrm{C}$. We performed such a PC by initially cooling the solution to $25.0^{\circ} \mathrm{C}$ to create supersaturation in the racemic solution. This supersaturation is equal toward the $\mathrm{L}$ asn and D-asn solid phases because the concentrations and solubilities of L-asn and D-asn are equal. Upon addition of L-asn seeds, the supersaturation for L-asn decreases as a result of $\mathrm{L}^{-}$ asn crystal growth, while D-asn remains in solution as long as no primary nucleation occurs. Therefore, the solution concentration of $\mathrm{L}$-asn decreases while that of $\mathrm{D}$-asn remains constant. The difference between the solution concentrations of D- and L-asn is monitored by a polarimeter measuring the optical rotation.

In Figure 4a, the optical rotation increases from $0^{\circ}$ in the initially racemic solution to $0.034^{\circ}$ in $10 \mathrm{~h}$. The increasingly
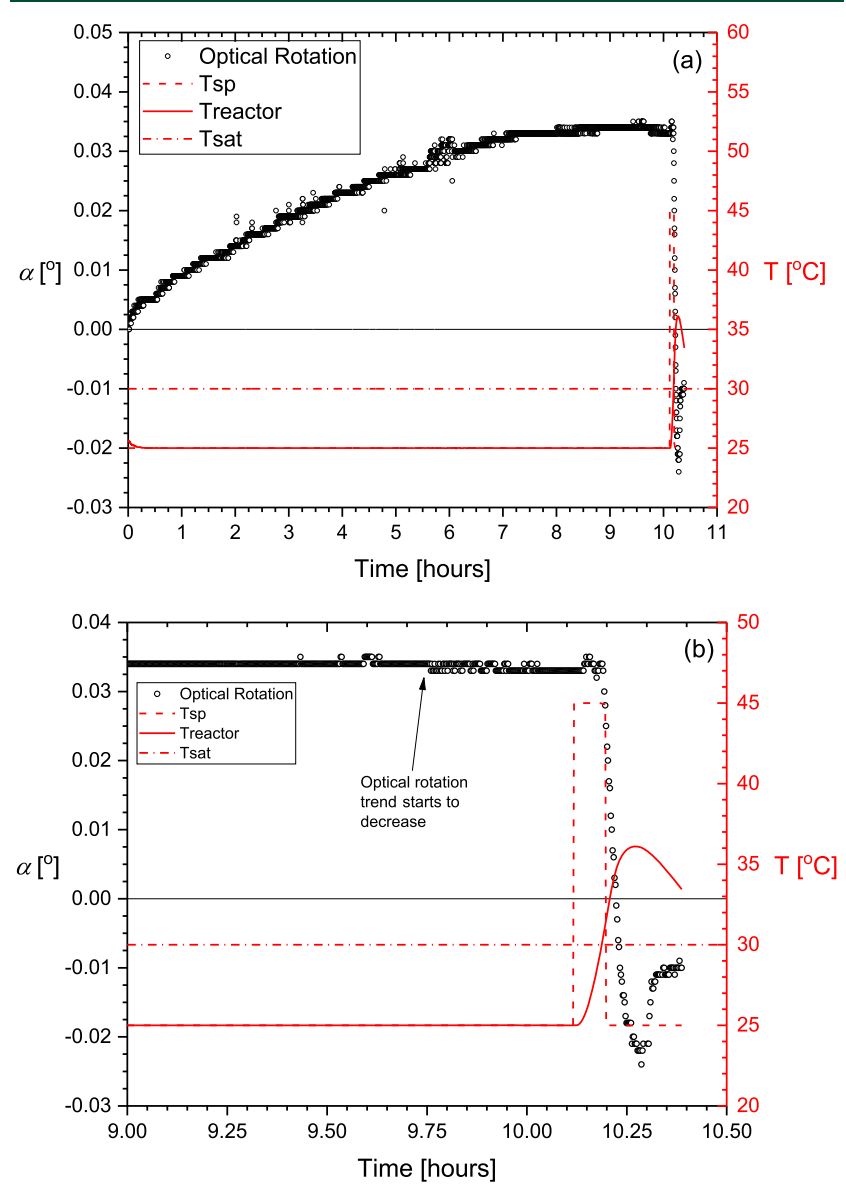

Figure 4. Profiles of optical rotation (black $O$ ), saturation temperature $T_{\text {sat }}$ (red dot-dashed line), set-point temperature $T_{\mathrm{sp}}$ (red dashed line), and actual crystallizer temperature $T_{\text {reactor }}$ (red solid line) during (a) the first $10 \mathrm{~h}$ of the batch PC process and (b) the attempted dissolution of nucleated counter enantiomer crystals by increasing the suspension temperature. The process had an initial supersaturation of $S=1.3$. The horizontal line at $0^{\circ}$ indicates the optical rotation value of a racemic mixture of enantiomers in solution.

positive optical rotation of the solution indicates that the solution is becoming more enriched in D-asn, and the difference between the enantiomer concentrations increases. This is due to growth of L-asn from seed crystals as L-asn is removed from solution. The rate of increase in the optical rotation decreases because of the decreasing supersaturation for L-asn growth, so that the growth rate decreases and the solute concentration of L-asn decreases at a lower rate as time passes.

However, a large supersaturation for D-asn still remains in the solution, and at some point in time D-asn crystals nucleate and grow. This is indicated by a decrease in the optical rotation, corresponding to a decrease in the concentration difference between the two enantiomers in solution. Figure $4 b$ shows that this optical rotation decrease happens shortly after $10 \mathrm{~h}$. 
Upon nucleation, the presence of D-asn can be detected only after its growth rate has reached levels such that the solution concentration difference between D-asn and L-asn is decreasing, resulting in a decrease in optical rotation. For this decrease to occur in a batchwise PC, the mass-based total growth rate of the D-asn crystalline phase has to be significantly larger than that of L-asn. If there is only a small amount of D-asn crystals present, for instance, right after nucleation of the first crystals, the mass-based total growth rate of D-asn can be smaller than that of L-asn, and the optical rotation might still rise. Thus, there is a time lag between the nucleation of the unwanted enantiomer crystals and the subsequent detection. This makes it difficult, using a polarimeter, to establish the exact time at which D-asn nucleates in such batchwise seeded preferential crystallizations. However, Figure 4a shows that in this case the drop in optical rotation is substantial in a short time, and therefore, we concluded that the unwanted nucleation in this experiment occurred shortly before this drop.

An attempt to alleviate the presence of the relatively small Dasn crystals by preferentially dissolving them by heating the suspension failed. In this experiment, all of the particles inside the vessel, including the seed crystals of L-asn that were added to the racemic solution, dissolved because of the difficulty of exactly controlling suspension the temperature, as shown by the decrease in the optical rotation value to below zero.

The productivity $(P)$ of the batch process was calculated to be $0.0185 \mathrm{~g} \mathrm{~g}^{-1} \mathrm{~h}^{-1}$ on the basis of a batch end time $\left(t_{\text {end }}\right)$ of $5.5 \mathrm{~h}$ using the following equation:

$$
P\left(t_{\text {end }}\right)=\frac{m_{\mathrm{p}}^{(\mathrm{L})}-m_{\mathrm{s}}^{(\mathrm{L})}}{m_{\mathrm{i}}^{(\mathrm{L})} t_{\text {end }}}
$$

where $m_{\mathrm{p}}^{(\mathrm{L})}$ is the mass of L-asn produced at $t_{\text {end }}, m_{\mathrm{s}}^{(\mathrm{L})}$ is the mass of L-asn seed crystals added at the start of the process, and $m_{\mathrm{i}}^{(\mathrm{L})}$ is the initial mass of L-asn in solution. A $t_{\text {end }}$ of $5.5 \mathrm{~h}$ was chosen since we were confident that the counter enantiomer D-asn had not crystallized at that point. The yield of the process $(Y)$ was calculated to be $44 \%$ using the following expression:

$$
Y\left(t_{\text {end }}\right)=\frac{m_{\mathrm{c}}^{(\mathrm{L})}}{m_{\mathrm{t}}^{(\mathrm{L})}} \times 100 \%
$$

where $m_{\mathrm{c}}^{(\mathrm{L})}$ is the actual mass of L-asn crystallized out at $t_{\text {end }}$ and $m_{\mathrm{t}}^{(\mathrm{L})}$ is the theoretical mass of $\mathrm{L}$-asn that would be crystallized out if the process were to reach equilibrium for Lasn.

An approach to alleviate the formation of D-asn crystals could be to simply increase the temperature to the saturation temperature of the system, $T_{\text {sat }}$. Since there will be an excess of $\mathrm{L}$-asn present due to the added seeds, all of the D-asn and L-asn would dissolve except for these seeds. However, this would mean that the system is simply being reset rather than being controlled. Since usually a small amount of seeds with a small average size is used, dissolution of the counter enantiomer crystals while retaining with the preferred enantiomer seed crystals has only a very small, difficult to control temperature region $\left(<1{ }^{\circ} \mathrm{C}\right)$. The approach could be improved by changing the method of heating; the use of microwave heaters has been shown to be an effective way to rapidly heat a lab-scale process/reaction and to provide greater control than conventional heating methods. ${ }^{34-37}$ Multiple heater-chillers with different set temperatures could also be used to improve rapid heating and cooling of the suspension.

\subsection{Concentration Control Approach for Continuous}

PC. The optical rotation results from a continuous preferential crystallization experiment with concentration control are shown in Figure 5a. In Figure 5b, we show the corresponding
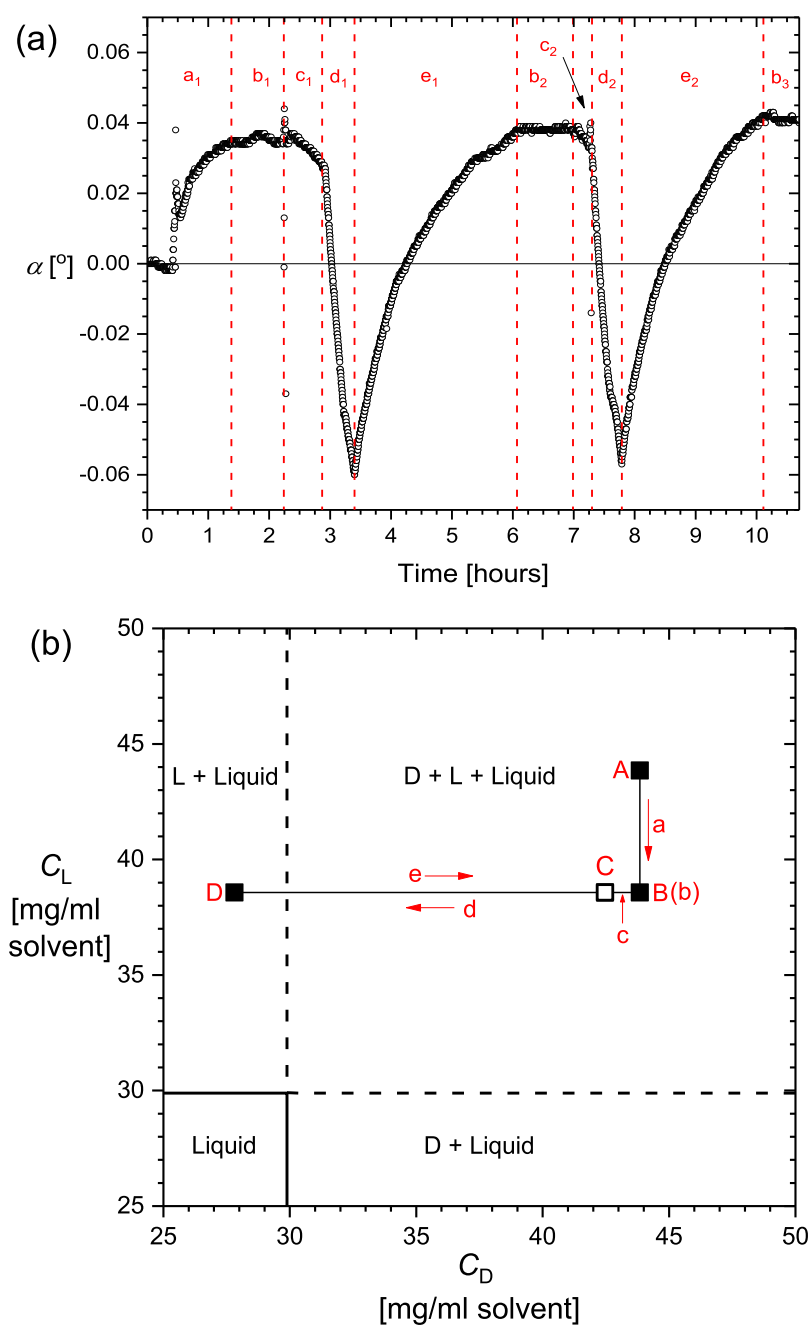

Figure 5. (a) Optical rotation results $(\mathrm{O})$ for the continuous $\mathrm{PC}$ of $\mathrm{L}-$ asn utilizing concentration control at a supersaturation ratio of $S=$ 1.45: $a_{1}=$ startup; $b_{1 / 2 / 3}=$ steady state; $c_{1 / 2}=$ nucleation and detection of $\mathrm{D}$-asn crystals; $d_{1 / 2}=$ application of switch to enantiopure feed to dissolve D-asn crystals; $e_{1 / 2}=$ switch back to the racemic feed and return to the steady state. Red dashed lines show the boundaries for each part of the process. The horizontal line at $0^{\circ}$ indicates the optical rotation value of a racemic mixture of enantiomers in solution. (b) Ternary phase diagram of $\mathrm{D}$ - and L-asn in water at $25.0^{\circ} \mathrm{C}$. The two solid segments of the lines show phase boundaries between solid and solid-liquid regions while the dashed lines represent the boundaries between two different solid-liquid phase regions. The point at which the two lines intersect is the eutectic point. A, B, C, and $\mathrm{D}$ are the operating points: $\mathrm{A}=$ racemic feed concentration $(87.7$ $\mathrm{mg} / \mathrm{mL}$ of solvent, $T_{\text {sat }}=35.0^{\circ} \mathrm{C}$ ); B = steady-state concentration ( $\mathrm{L}-$ asn concentration $=38.57 \mathrm{mg} / \mathrm{mL}$ of solvent); $\mathrm{C}=$ concentration at the time of the feed switch after detection of the presence of D-asn; D $=$ the concentration after the controlling action to dissolve unwanted D-asn (27.81 mg of D-asn/mL of solvent). a, b, c, d, and e are the process stages: $\mathrm{a}=$ startup; $\mathrm{b}=$ steady state; $\mathrm{c}=$ nucleation and growth of D-asn; $d$ = application of the switch to the enantiopure feed; $\mathrm{e}=$ switch back to the racemic feed. 
liquid-phase trajectory during the continuous PC process, focusing on the area of the ternary phase diagram around the eutectic point. The startup of the process takes place in the first 80 min (1.33 residence times). In the startup region (Figure $5 a$, region $a_{1}$ ) the optical rotation is initially at $0^{\circ}$ because of the presence of a supersaturated racemic solution in the crystallizer. Point $\mathrm{A}$ in Figure $5 \mathrm{~b}$ shows the racemic feed composition $(87.7 \mathrm{mg} / \mathrm{mL}$ of solvent $)$ entering the crystallizer. After seed crystals of L-asn are added, the optical rotation increases as the seed crystals grow and, as a result of secondary nucleation, new seed crystals are created, removing L-asn solute from solution. Growth of the added L-asn seeds is represented by a change in the liquid composition from point $\mathrm{A}$ to point $\mathrm{B}$ in Figure 5b, and the optical rotation levels off upon approaching steady-state region $b_{1}$ in Figure 5a.

In steady-state region $b_{1}$ the continuous feed, growth, and secondary nucleation and suspension removal allow a steady state to develop with a solution concentration of $C_{\mathrm{L}}=38.57$ $\mathrm{mg}$ of L-asn $/ \mathrm{mL}$ of solvent and $C_{\mathrm{D}}=43.5 \mathrm{mg}$ of D-asn $/ \mathrm{mL}$ of solvent (Figure $5 \mathrm{~b}$ ), as determined by gravimetric and subsequent HPLC analyses. This corresponds to a constant optical rotation value of around $0.035^{\circ}$ in the steady-state regions $b_{1}, b_{2}$, and $b_{3}$ in Figure 5a. If the system reached equilibrium, i.e., if all possible L-asn crystallized from solution, an optical rotation value of $0.080^{\circ}$ would have been obtained.

However, this steady state is metastable because of the prevailing supersaturation for the counter enantiomer crystals, and as in the batch PC process, they will eventually crystallize. The optical rotation at steady state in the continuous PC process is constant, and therefore, the formation of unwanted counter enantiomer crystals is easily observed as a deviation from the steady-state optical rotation with much less delay. The change in steady-state value was chosen to be more than $0.004^{\circ}$. In the continuous case, the change in optical rotation trajectory does not depend on the relative growth rates of $\mathrm{L}$-asn and D-asn once L-asn has reached the steady state. We merely need a detectable decrease in the steady-state optical rotation, which is determined by the capabilities of the instrument. This decrease in optical rotation is detected at the beginning of region $c_{1}$. Upon nucleation and growth of $D$-asn, the concentration of D-asn in the solution decreases, and we see a decrease in optical rotation (Figure 5a, region $\mathrm{c}_{1}$ ). In Figure $5 \mathrm{~b}$, this corresponds to a change in solution trajectory from point $\mathrm{B}$ toward point $\mathrm{C}$ (giving a change in optical rotation value from 0.035 to $0.028^{\circ}$ ). In practice, of course, such a large change in optical rotation before application of the control would not occur, and region $\mathrm{c}$ in Figure 5a would be as small as possible. However, we allowed some time before applying the control so that the deviation from steady state was obvious.

At the start of region $d_{1}$, to dissolve all of the formed D-asn crystals while keeping the feed concentration of L-asn constant, the racemic feed is switched off, and an enantiopure feed is switched on for a predetermined duration calculated by eq 1 . In this case, in order to reach a target undersaturated concentration of $27.0 \mathrm{mg}$ of $\mathrm{D}-\mathrm{asn} / \mathrm{mL}$ of solvent, the feed was switched for $28 \mathrm{~min}$ and $36 \mathrm{~s}$. Doing this reduced the concentration of D-asn in the crystallizer solution so that the solution became undersaturated, and any D-asn crystals in the suspension preferentially dissolved. This transition to an undersaturated region with respect to D-asn is shown in the phase diagram by region $d_{1}$ (Figure 5), finally arriving in point $\mathrm{D}$ in Figure $5 \mathrm{~b}$. As only L-asn solution is fed to the crystallizer during this period, the D-asn concentration in the vessel decreases via dilution, resulting in a drop in optical rotation visible in region $d_{1}$ (Figure 5a). Since this reduction in the Dasn concentration results in an excess of L-asn with respect to D-asn in solution, the optical rotation value eventually becomes negative. There is a subtle change in the slope observed toward the end of regions $d_{1}$ and $d_{2}$, which could be explained by Dasn reaching undersaturated conditions, under which D-asn crystals dissolve rather than grow.

The growth of L-asn is inhibited by the presence of D-asn solute. During periods of lower concentration of D-asn, growth of L-asn therefore may be slightly faster, ${ }^{14}$ and the crystallizer may operate slightly closer to equilibrium with respect to L-asn. Therefore, there might be a small deviation from steady state with respect to the L-asn concentration in solution in regions $\mathrm{d}_{1}$ and $\mathrm{d}_{2}$ in Figure 5a. However, because of the high concentration of D-asn, this deviation is not substantial and does not affect the control strategy negatively.

Once the target concentration of $\mathrm{D}$-asn has been reached, all of the solid D-asn has dissolved since the feed is switched for a period of time that ensures that the target concentration of $D$ asn is well in the undersaturated region and the crystals have sufficient time to dissolve. The feed is then switched from the enantiopure feed back to the racemic feed. As D-asn in solution is added again to the vessel (along with L-asn), the optical rotation increases and approaches steady-state region $b_{2}$. The return to a steady state with respect to optical rotation was relatively slow because of the asymptotic nature of reaching the same concentration of D-asn in solution in the crystallizer as in the feed. More importantly, the suspension consists only of Lasn crystals, and therefore, an enantiopure product is obtained in this region as well. The cycle then repeats showing one more nucleation event in $c_{2}$ and a correction region $d_{2}$, demonstrating the robustness and reproducibility of the control strategy within the same process run.

Figure 6 shows the enantiomeric excess results from the HPLC analysis carried out on the solid product. The solid phase consisted of only L-asn during steady-state regions $b_{1}$

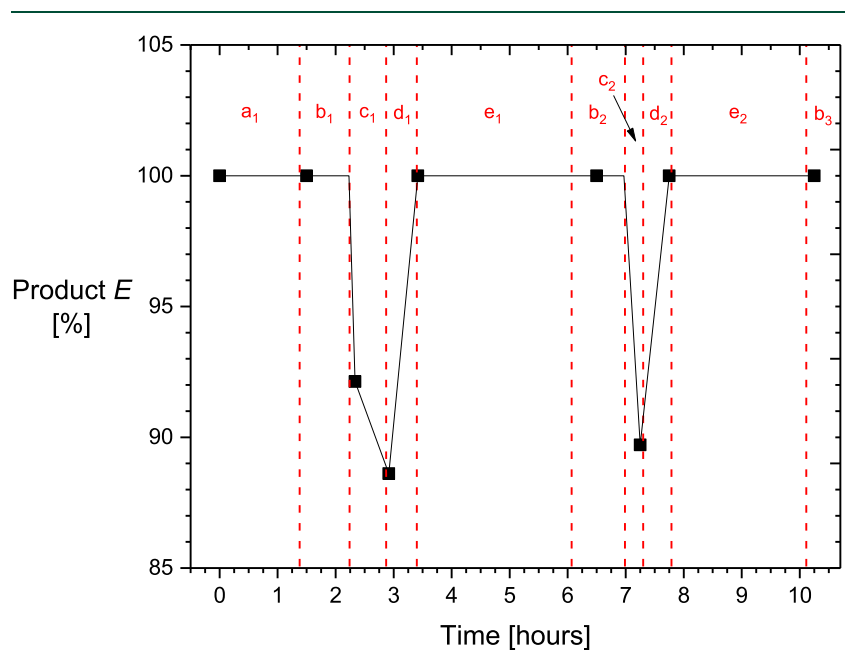

Figure 6. Solid product enantiomeric excess results (ם) from chiral HPLC analysis on the product collected at each sample point for the continuous crystallization experiment at a supersaturation ratio $S=$ 1.45. The value at time $=0$ is the enantiopurity of the seed crystals used in the continuous preferential crystallization. The red dashed lines show the boundaries between periods in the process shown in Figure 5. The results show that enantiopure product is obtained after application of the control. The black solid line is a guide to the eye. 
and $b_{2}$. The solid contained as much as $12 \% \mathrm{D}$-asn in regions $\mathrm{c}_{1}$ and $c_{2}$ after counter enantiomer nucleation but before the control action. An increasing amount of D-asn was present in the sample collected in region $\mathrm{c}_{1}$, consistent with the substantially decreasing optical rotation value of the solution in that region. All of the D-asn was dissolved by the end of $d_{1}$ and $\mathrm{d}_{2}$, and the product enantiopurity returned to $100 \%$ after the implementation of the control strategy, verifying its effectiveness.

Compared with a standard batchwise preferential crystallization, the ability to detect and correct for the formation of the undesired enantiomer allows the process to potentially operate at higher concentration and thus higher productivity. The magnitude of this increase depends on the rise in productivity compared with the higher demand for enantiopure feed due to increases in the nucleation frequency of the undesired enantiomer. To illustrate this, we conducted two further continuous experiments run at the same crystallization temperature $\left(25.0^{\circ} \mathrm{C}\right)$, but one was run at a higher feed concentration $(S=1.60)$ and the other at a lower feed concentration $(S=1.20)$. The optical rotation profiles of these experiments are shown in Figure $7 a$ and Figure $7 b$, respectively. In the experiment with $S=1.60$, the steadystate period was much shorter (approximately $0.2 \mathrm{~h}$ ) than in the previous experiment with $S=1.45$ (approximately $0.85 \mathrm{~h}$ ), meaning that use of the control action would be more frequent. However, in the experiment with the lower supersaturation $S=1.20$ (Figure $7 \mathrm{~b}$ ), the steady-state period lasted around $10 \mathrm{~h}$ before nucleation of the counter enantiomer occurred, meaning that the control action would be used much less frequently, and thus, less enantiopure feed would be required for correction. Unfortunately, some accumulation of larger crystals occurred in this experiment, as indicated in Figure $7 \mathrm{~b}$. This was due to circulation of large crystals in the lower half of the reactor. Since these crystals did not leave the crystallization vessel, they continued to grow while the secondary nucleation rate decreased. Thus, more and more L-asn was removed from solution, giving an increasing excess of D-asn in solution, causing the optical rotation to increase. The agitation speed was increased in order to suspend these crystals more and allow them to leave the reactor as well as to stimulate secondary nucleation. As a result, the optical rotation returned to the steady-state value. The measured optical rotation fluctuated between 9 and $11 \mathrm{~h}$ as a result of bubbles in the sample line. A solid sample was taken during this time to confirm that enantiopure product was still being produced (see the Supporting Information).

The solution trajectories for the three continuous PC experiments are shown in the corresponding ternary phase diagram in Figure 8, in which the solution trajectory with $S=$ 1.45 explained in Figure 6 is compared with those for $S=1.20$ and $S=1.60$. As the supersaturation decreases, the steady-state concentration of the process is closer to the racemic composition. Furthermore, the difference between the steady-state value and the target D-asn concentration is smaller as the initial supersaturation decreases, meaning that less pure material is required for implementation of the control strategy.

\section{DISCUSSION}

The economic feasibility of such a process control approach depends on the amount of desired enantiomer invested in the enantiopure feed during the control action compared with the pure enantiomer recovered as total crystalline product. These
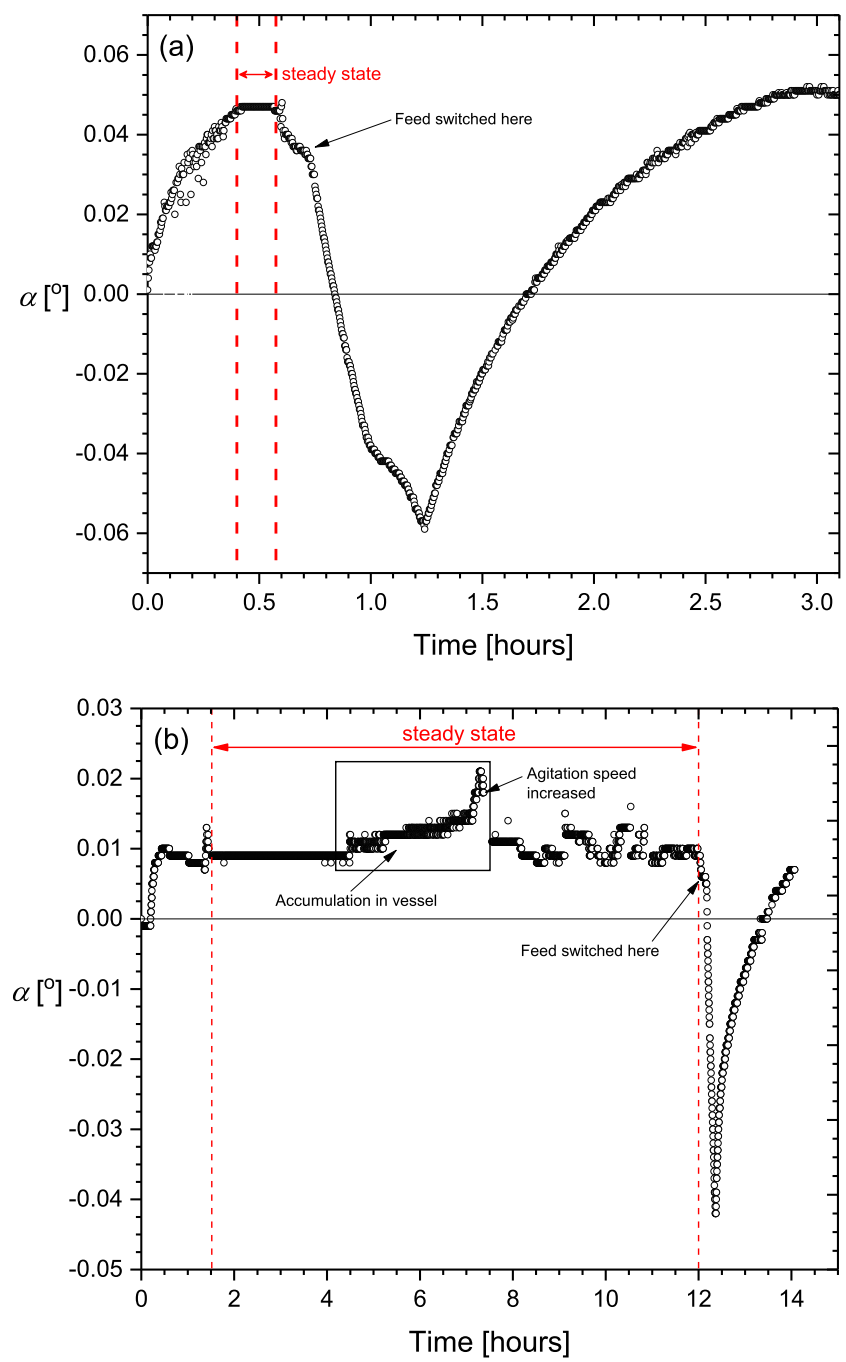

Figure 7. Optical rotation results $(O)$ from continuous crystallization experiments carried out with initial supersaturation ratios of (a) $S=$ 1.60 and (b) $S=1.20$, showing the steady-state region of each process. The horizontal lines at $0^{\circ}$ indicate the optical rotation value of a racemic mixture of enantiomers in solution.

in turn depend on the production rate of the desired enantiomer and the nucleation frequency of the counter enantiomer crystals. A high nucleation frequency of the undesired enantiomer means that the steady state cannot be maintained for substantial periods of time and many controlling actions are needed. The nucleation frequency will decrease with decreasing steady-state supersaturation of the undesired enantiomer. The production rate of the preferred enantiomer is enhanced by high secondary nucleation and growth rates, which increase with increasing supersaturation of the preferred enantiomer. Thus, there is a balance between the high supersaturation toward the preferred enantiomer and the low supersaturation toward the unwanted enantiomer.

The controlling action of switching the feed from racemic to enantiopure is effective in dissolving the counter enantiomer. During the process, since L-asn continues to be produced, pure product can be collected except for relatively short periods when crystalline $\mathrm{D}$-asn is present in the crystallizer, for instance, in regions $c_{1}, d_{1}, c_{2}$, and $d_{2}$ in Figure 6. During regions $c_{1}$ and $c_{2}$, the suspension leaving the crystallizer can, after dissolution, be recycled back into the racemic feed to avoid product loss 


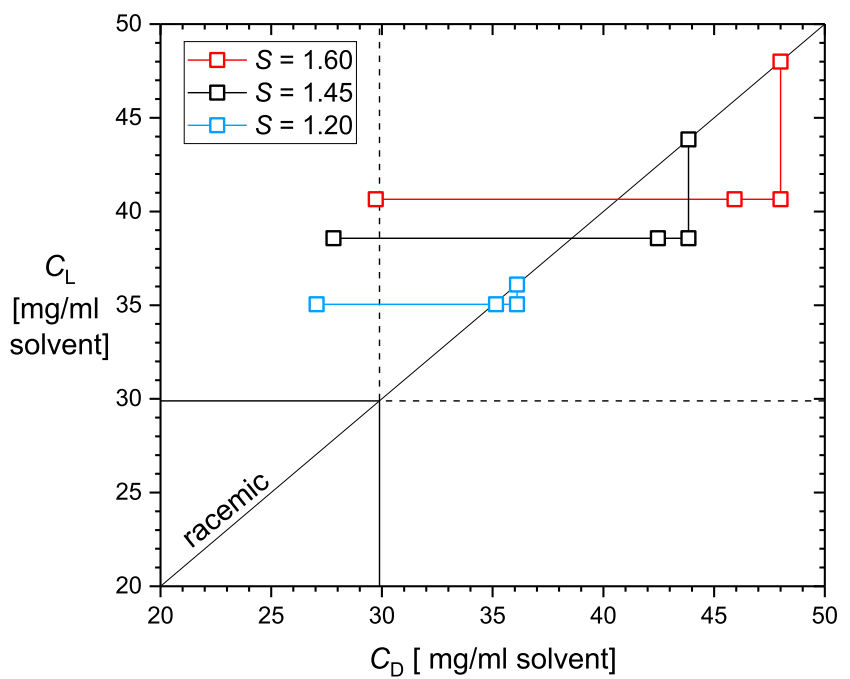

Figure 8. Ternary phase diagram showing the solution trajectories for the control strategy at different supersaturation ratios: $(\square) S=1.60$, ( $\square$ ) $S=1.45$, and $(\square) S=1.20$.

since the overall outgoing suspension stream has the same composition as the feed. However, in regions $d_{1}$ and $d_{2}$ in Figure 5, when the feed has been switched to the enantiopure feed of L-asn, the overall outgoing suspension stream composition becomes more enriched with L-asn over time because of a decrease in the overall D-asn concentration. Therefore, after recycling of the suspension leaving the crystallizer during regions $d_{1}$ and $d_{2}$, the feed solution will contain a slightly lower concentration of D-asn compared with L-asn. This would cause the supersaturation and therefore the nucleation frequency of D-asn to decrease, and thus, the process would become more stable. Product can be collected again once the feed is switched back to the racemic feed (Figure 5, regions $\mathrm{e}_{1}$ and $\mathrm{e}_{2}$ ).

4.1. Productivity and Yield. Table 1 summarizes the productivity and yield results obtained for each supersaturation run. The yield and productivity calculations were carried out on the basis of one control cycle, consisting of the following regions in Figure 5: steady state $b$, counter enantiomer detection c, control action $d$, and return to steady state e. The productivity of L-asn production for one cycle of the process, $P_{\mathrm{L}}^{+}\left(t_{\text {cycle }}\right)$, can be determined using eq 4 :

$$
P_{\mathrm{L}}^{+}\left(t_{\text {cycle }}\right)=\frac{m_{\mathrm{p}}^{(\mathrm{L})}}{V_{\mathrm{r}} \cdot t_{\text {cycle }}}
$$

Where $m_{\mathrm{p}}^{(\mathrm{L})}$ is the mass of $\mathrm{L}$-asn crystal product in the product outlet stream in one control cycle (the product obtained in regions $\mathrm{b}$ and $\mathrm{e}), V_{\mathrm{r}}$ is the operating volume of the reactor, and $t_{\text {cycle }}$ is the cycle time from the start of region $\mathrm{b}$ to the end of region e. This cycle time for the experiment with $S=1.45$ was $4.94 \mathrm{~h}$, as can be determined from Figure 5a. In contrast, the use of L-asn per cycle per unit volume in the control action, $P_{\mathrm{L}}^{-}\left(t_{\text {cycle }}\right)$, is determined by

$$
P_{\mathrm{L}}^{-}\left(t_{\text {cycle }}\right)=\frac{m_{\mathrm{c}}^{(\mathrm{L})}}{V_{\mathrm{r}} \cdot t_{\text {cycle }}}
$$

where $m_{\mathrm{c}}^{(\mathrm{L})}$ is the mass of L-asn in the pure solution during the control action in one control cycle (the amount of product used in region $d$ ). The net productivity of one control cycle of the process, $P_{\mathrm{L}}\left(t_{\text {cycle }}\right)$, is therefore determined by

$$
P_{\mathrm{L}}\left(t_{\text {cycle }}\right)=P_{\mathrm{L}}^{+}-P_{\mathrm{L}}^{-}
$$

The net percentage yield of L-asn obtained from each experiment can be calculated using eq 7 :

$$
Y_{\mathrm{L}}\left(t_{\text {cycle }}\right)=\left(\frac{m_{\mathrm{p}}^{(\mathrm{L})}-m_{\mathrm{c}}^{(\mathrm{L})}}{m_{\mathrm{t}}^{(\mathrm{L})}}\right) \times 100 \%
$$

where $m_{\mathrm{t}}$ is the theoretical mass of L-asn that can be crystallized out in one full cycle if the system reaches equilibrium.

The productivity values $P_{\mathrm{L}}^{+}$and $P_{\mathrm{L}}^{-}$can be plotted as functions of $S$, as shown in Figure 9. The $P_{\mathrm{L}}^{+}$value is shown to have a close to linear correlation with $S$ : as $S$ increases, the $P_{\mathrm{L}}^{+}$ value increases. The $P_{\mathrm{L}}^{-}$value, however, increases exponentially with increasing $S$. As long as $P_{\mathrm{L}}^{+}$is greater than $P_{\mathrm{L}}^{-}$, the process has a net positive productivity value. This was the case for $S=$ 1.20 , where a net productivity of $0.38 \mathrm{~g} \mathrm{~L}^{-1} \mathrm{~h}^{-1}$ was achieved. Around $40 \%$ of the product had to be used for the control action. Since there is remaining supersaturation in the outgoing solution at this $S$ value, finally a yield of $19.4 \%$ was achieved.

The relative difference between these $P_{\mathrm{L}}^{+}$and $P_{\mathrm{L}}^{-}$values (which ultimately dictates the net productivity of the process) can be changed by increasing the growth rate of the preferred enantiomer (i.e., increasing $P_{\mathrm{L}}^{+}$) and decreasing the nucleation rate of the unwanted enantiomer (i.e., decreasing $P_{\mathrm{L}}^{-}$). Such a change can be achieved by enriching the feed with the preferred enantiomer. This could be done by recycling a part of the product into the feed. One way of doing so would be to recycle the remaining solution from region $d$ in Figure 5a containing decreased $\mathrm{D}$-asn concentrations back into the feed. Decreasing the $P_{\mathrm{L}}^{-}$value could also be achieved by using additives to inhibit growth of the unwanted enantiomer. Several such additives were found, such as D-aspartic acid and D-glutamic acid. ${ }^{14}$

Table 1. Summary of the Production and Use of L-asn, Productivities, and Yields Obtained for Supersaturations of $S=1.20$, 1.45 , and $1.60^{a}$

$\begin{array}{cccccccc}S & m_{\mathrm{p}}^{(\mathrm{L})}[\mathrm{g}] & m_{\mathrm{c}}^{(\mathrm{L})}[\mathrm{g}] & t_{\text {cycle }}[\mathrm{h}] & Y_{\mathrm{L}}\left(t_{\text {cycle }}\right)[\%] & P_{\mathrm{L}}^{+}\left(t_{\text {cycle }}\right)\left[\mathrm{g} \mathrm{L}^{-1} \mathrm{~h}^{-1}\right] & P_{\mathrm{L}}^{-}\left(t_{\text {cycle }}\right)\left[\mathrm{g} \mathrm{L}^{-1} \mathrm{~h}^{-1}\right] & P_{\mathrm{L}}\left(t_{\text {cycle }}\right)\left[\mathrm{g} \mathrm{L}^{-1} \mathrm{~h}^{-1}\right] \\ 1.20 & 3.007 & 1.817 & 12.48 & 19.4 & 0.96 & 0.58 & 0.38 \\ 1.45 & 4.825 & 4.804 & 4.94 & 0.15 & 3.91 & 3.89 & 0.017 \\ 1.60 & 3.044 & 6.299 & 2.48 & -18.0 & 4.90 & 10.15 & -5.24\end{array}$

${ }^{a}$ For each experiment, the residence time, $\tau$, was $60 \mathrm{~min}$, and the seed mass added at startup was $2 \mathrm{~g} . m_{\mathrm{p}}^{(\mathrm{L})}$ is the mass of $\mathrm{L}$-asn produced; $m_{\mathrm{c}}^{(\mathrm{L})}$ is the mass of L-asn used during correction; $Y_{\mathrm{L}}\left(t_{\text {cycle }}\right)$ is the net percent yield of $\mathrm{L}$-asn produced for one cycle of the process; $P_{\mathrm{L}}^{+}\left(t_{\text {cycle }}\right)$ is the productivity of $\mathrm{L}$-asn produced for one cycle of the process; $P_{\mathrm{L}}^{-}\left(t_{\text {cycle }}\right)$ is the productivity of $\mathrm{L}$-asn used for the correction during the process; $P_{\mathrm{L}}\left(t_{\text {cycle }}\right)=P_{\mathrm{L}}^{+}\left(t_{\text {cycle }}\right)-$ $P_{\mathrm{L}}^{-}\left(t_{\text {cycle }}\right)$ is the net productivity for one cycle. 


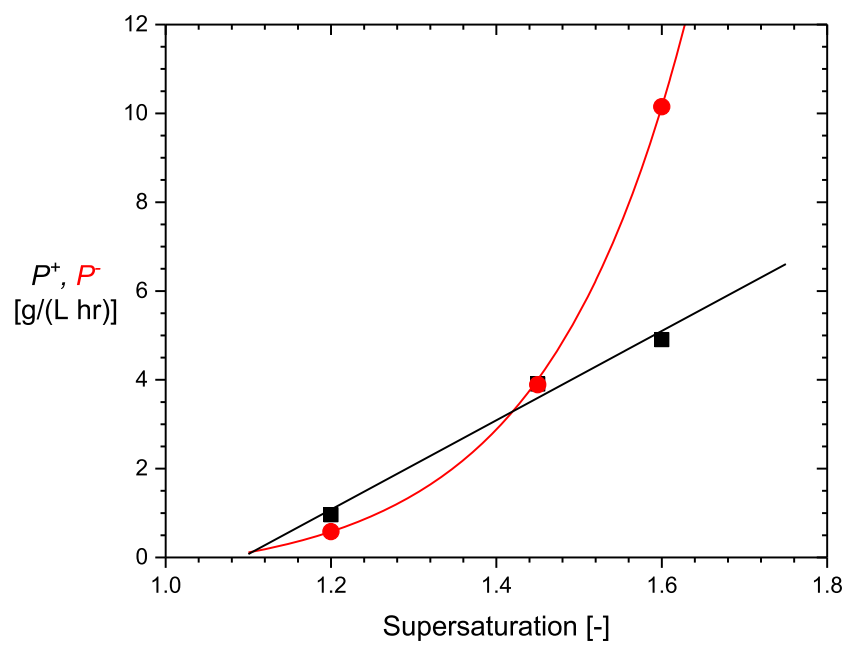

Figure 9. Correlation between the mass of L-asn produced per unit volume per cycle time, $P_{\mathrm{L}}^{+}$(black $\left.\boldsymbol{\square}\right)$, and the mass of L-asn used during the correction (region $d$ in Figure 5) per unit volume per cycle time, $P_{\mathrm{L}}^{-}$(red - ), as functions of supersaturation ratio, $S$. A net positive productivity value $P_{\mathrm{L}}\left(t_{\text {cycle }}\right)$ requires $P_{\mathrm{L}}^{+}>P_{\mathrm{L}}^{-}$. Lines are guides to the eye.

As expected, a supersaturation ratio of 1.60 gives the most inefficient process when using the control strategy. As shown in Table 1 , a net yield of $-18.0 \%$ is obtained, and so use of the control strategy is inefficient. A small positive net yield of $0.15 \%$ is obtained at a supersaturation ratio of 1.45 . A good positive net yield of $19.4 \%$ is obtained for the supersaturation ratio of 1.20 . The process can still be further optimized by determining the supersaturation which gives the maximum net yield for the process, as this work is only a demonstration of the control strategy. However, the presented results do not account for recycling of any solution, which in practice would most certainly be applied so as not to waste valuable product.

4.2. Process Improvement. The efficiency and yield of the process can be improved by recycling the mother liquor produced during the process. A schematic of a potential process setup with such a recycle loop is shown in Figure 10. However, since the mother liquor in the outlet stream during regions $b$ and $e$ in Figure 5 has an excess of D-asn in the solution, a further crystallization step must be carried out in order to obtain a solution of racemic composition again. A portion of the enantiopure product (denoted by $\mathrm{X}$ in Figure 10) can be used along with solvent to make the enantiopure feed solution for the control strategy. During regions $\mathrm{c}$ and $\mathrm{d}$ in Figure 5, the solid (contaminated with D-asn crystals) and mother liquor solution can be recycled back directly to the feed solution (blue dashed line in Figure 10). During this period, as discussed in section 4, the solution will become more enriched with L-asn over time, thus reducing the nucleation frequency of D-asn. For such a process to be economically feasible, the less expensive enantiomer should be crystallized in the first crystallization vessel, since part of the produced solid will be used for the enantiopure feed. Furthermore, utilizing the control strategy in a coupled batch or continuous setup similar to one used by Galan et al. ${ }^{29}$ could also improve the overall process efficiency. In such a setup, the supersaturation of the counter enantiomer is reduced since it has been previously crystallized in a coupled vessel before entering the crystallizer seeded with the preferred enantiomer. Therefore, steady-state periods of preferred enantiomer production would be

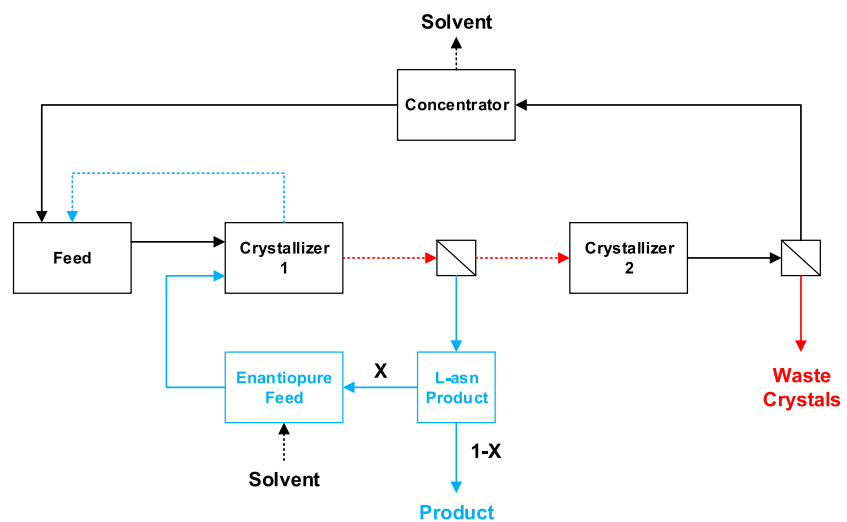

Figure 10. Schematic of a potential setup for improving the efficiency of the control strategy. By the use of a second crystallization vessel, the counter enantiomer can be crystallized to return the solution to a racemic composition, after which the solution can be recycled into the feed vessel via a concentrating vessel so that waste can be reduced. Legend: (black solid line) racemic solution; (black dashed line) pure solvent; (blue solid line) pure L-asn solid or solution; (blue dashed line) enriched L-asn suspension recycled during region d in Figure 5; (red solid line) pure D-asn solid; (red dashed line) enriched D-asn solution.

extended, meaning that fewer uses of the controlling action would be needed, and in turn, higher net yields could be obtained.

\section{CONCLUSIONS}

We have demonstrated control over a continuous preferential cooling crystallization process using a new approach. In this approach, we utilized an additional feed tank containing enantiopure solution to undersaturate the undesired counter enantiomer crystals when they appear in the continuous process. The continuous approach is easy to scale because the control strategy relies on movement through regions of the phase diagram by adjustment of the composition rather than on the kinetics of dissolution. The control strategy has also demonstrated reproducibility over several cycles and runs, correcting for the nucleation of the undesired enantiomer. The benefit of this strategy comes from being able to operate an MSMPR reactor at higher supersaturation compared with an uncontrolled process. Using a single-stage MSMPR reactor is most likely not the most efficient application of this strategy. However, it also allows for new process arrangements such as combination with a coupled batch setup or an MSMPR reactor cascade for improved productivity. The control strategy should be optimized for the chosen system to find the supersaturation that generates the maximum yield, since this will depend on the growth and nucleation kinetics of the system of interest.

\section{ASSOCIATED CONTENT}

\section{S Supporting Information}

The Supporting Information is available free of charge on the ACS Publications website at DOI: 10.1021/acs.oprd.9b00275.

Polarimeter monitoring experiments, feed switch calculation derivation, and detailed HPLC calibration and results (PDF)

\section{AUTHOR INFORMATION}

\section{Corresponding Author}

*E-mail: joop.terhorst@strath.ac.uk. 


\section{ORCID $\odot$}

Andrew S. Dunn: 0000-0002-8417-8468

Vaclav Svoboda: 0000-0002-2386-7112

Joop H. ter Horst: 0000-0003-0118-2160

\section{Notes}

The authors declare no competing financial interest.

\section{ACKNOWLEDGMENTS}

The authors thank Jerzy Dziewierz for his help with instrument communications, Johannes Hoffmann for his advice on the continuous filtration of the polarimeter samples, and Laura Harvey for all of her help with HPLC setup and samples. The authors also thank the EPSRC and the Doctoral Training Centre in Continuous Manufacturing and Crystallization (Grant EP/K503289/1) for funding this work. The authors acknowledge that this work was carried out in the CMAC National Facility supported by a UKRPIF award from HEFCE (Grant HH13054).

\section{REFERENCES}

(1) Jacques, J.; Collet, A. Enantiomers, Racemates and Resolutions; John Wiley \& Sons, 1981.

(2) Köllges, T.; Vetter, T. Model-Based Analysis of Continuous Crystallization/Reaction Processes Separating Conglomerate Forming Enantiomers. Cryst. Growth Des. 2017, 17 (1), 233-247.

(3) Chhabra, N.; Aseri, M. L.; Padmanabhan, D. A Review of Drug Isomerism and Its Significance. Int. J. Appl. basic Med. Res. 2013, 3 (1), $16-18$.

(4) Maier, N. M.; Franco, P.; Lindner, W. Separation of Enantiomers: Needs, Challenges, Perspectives. J. Chromatogr. A 2001, 906 (1-2), 3-33.

(5) Viedma, C. Chiral Symmetry Breaking During Crystallization: Complete Chiral Purity Induced by Nonlinear Autocatalysis and Recycling. Phys. Rev. Lett. 2005, 94 (6), 065504.

(6) Spix, L.; van Enckevort, W. J. P.; van der Wal, L. J. M.; Meekes, H.; Vlieg, E. Resolution of Asparagine in a Coupled Batch Grinding Process: Experiments and Modelling. CrystEngComm 2016, 18 (48), 9252-9259.

(7) Xiouras, C.; Ter Horst, J. H.; Van Gerven, T.; Stefanidis, G. D. Coupling Viedma Ripening with Racemic Crystal Transformations: Mechanism of Deracemization. Cryst. Growth Des. 2017, 17, 49654976.

(8) Sögütoglu, L.-C.; Steendam, R. R. E.; Meekes, H.; Vlieg, E.; Rutjes, F. P. J. T. Viedma Ripening: A Reliable Crystallisation Method to Reach Single Chirality. Chem. Soc. Rev. 2015, 44 (19), 6723-6732.

(9) Fogassy, E.; Nógrádi, M.; Kozma, D.; Egri, G.; Pálovics, E.; Kiss, V. Optical Resolution Methods. Org. Biomol. Chem. 2006, 4 (16), 3011-3030.

(10) Mane, S. Racemic Drug Resolution: A Comprehensive Guide. Anal. Methods 2016, 8 (42), 7567-7586.

(11) Lorenz, H.; Seidel-Morgenstern, A. Processes to Separate Enantiomers. Angew. Chem., Int. Ed. 2014, 53, 1218-1250.

(12) Coquerel, G. Preferential Crystallization. Top. Curr. Chem. 2006, 269, 1-51.

(13) Petruševska-Seebach, K.; Seidel-Morgenstern, A.; Elsner, M. P. Preferential Crystallization of L-Asparagine in Water. Cryst. Growth Des. 2011, 11 (6), 2149-2163.

(14) Kongsamai, P.; Maneedaeng, A.; Flood, C.; ter Horst, J. H.; Flood, A. E. Effect of Additives on the Preferential Crystallization of LAsparagine Monohydrate. Eur. Phys. J.: Spec. Top. 2017, 226 (5), 823-835.

(15) Steendam, R. R. E.; ter Horst, J. H. Continuous Total Spontaneous Resolution. Cryst. Growth Des. 2017, 17 (8), 44284436.
(16) Srisanga, S.; ter Horst, J. H. Racemic Compound, Conglomerate, or Solid Solution: Phase Diagram Screening of Chiral Compounds. Cryst. Growth Des. 2010, 10 (4), 1808-1812.

(17) Elsner, M. P.; Menéndez, D. F.; Muslera, E. A.; SeidelMorgenstern, A. Experimental Study and Simplified Mathematical Description of Preferential Crystallization. Chirality 2005, 17 (S1), S183-S195.

(18) Rougeot, C.; Hein, J. E. Application of Continuous Preferential Crystallization to Efficiently Access Enantiopure Chemicals. Org. Process Res. Dev. 2015, 19 (12), 1809-1819.

(19) Levilain, G.; Coquerel, G. Pitfalls and Rewards of Preferential Crystallization. CrystEngComm 2010, 12 (7), 1983.

(20) Lorenz, H.; Perlberg, A.; Sapoundjiev, D.; Elsner, M. P.; SeidelMorgenstern, A. Crystallization of Enantiomers. Chem. Eng. Process. 2006, 45 (10), 863-873.

(21) Li, J.; Lai, T. C.; Trout, B. L.; Myerson, A. S. Continuous Crystallization of Cyclosporine: Effect of Operating Conditions on Yield and Purity. Cryst. Growth Des. 2017, 17, 1000-1007.

(22) Alvarez, A. J.; Singh, A.; Myerson, A. S. Crystallization of Cyclosporine in a Multistage Continuous MSMPR Crystallizer. Cryst. Growth Des. 2011, 11 (10), 4392-4400.

(23) Baxendale, I. R.; Braatz, R. D.; Hodnett, B. K.; Jensen, K. F.; Johnson, M. D.; Sharratt, P.; Sherlock, J.-P.; Florence, A. J. Achieving Continuous Manufacturing: Technologies and Approaches for Synthesis, Workup, and Isolation of Drug Substance May 20-21, 2014 Continuous Manufacturing Symposium. J. Pharm. Sci. 2015, 104, 781-791.

(24) Mascia, S.; Heider, P. L.; Zhang, H.; Lakerveld, R.; Benyahia, B.; Barton, P. I.; Braatz, R. D.; Cooney, C. L.; Evans, J. M. B.; Jamison, T. F.; et al. End-to-End Continuous Manufacturing of Pharmaceuticals: Integrated Synthesis, Purification, and Final Dosage Formation. Angew. Chem., Int. Ed. 2013, 52 (47), 12359-12363.

(25) Plumb, K. Continuous Processing in the Pharmaceutical Industry: Changing the Mind Set. Chem. Eng. Res. Des. 2005, 83 (6), 730-738.

(26) Myerson, A. S.; Krumme, M.; Nasr, M.; Thomas, H.; Braatz, R. D. Control Systems Engineering in Continuous Pharmaceutical Manufacturing May 20-21, 2014 Continuous Manufacturing Symposium. J. Pharm. Sci. 2015, 104 (3), 832-839.

(27) Wang, J.; Li, F.; Lakerveld, R. Process Intensification for Pharmaceutical Crystallization. Chem. Eng. Process. 2018, 127, 111126.

(28) Chaaban, J. H.; Dam-Johansen, K.; Skovby, T.; Kiil, S. Separation of Enantiomers by Continuous Preferential Crystallization: Experimental Realization Using a Coupled Crystallizer Configuration. Org. Process Res. Dev. 2013, 17 (8), 1010-1020.

(29) Galan, K.; Eicke, M. J.; Elsner, M. P.; Lorenz, H.; SeidelMorgenstern, A. Continuous Preferential Crystallization of Chiral Molecules in Single and Coupled Mixed-Suspension Mixed-ProductRemoval Crystallizers. Cryst. Growth Des. 2015, 15 (4), 1808-1818.

(30) Alvarez Rodrigo, A.; Lorenz, H.; Seidel-Morgenstern, A. Online Monitoring of Preferential Crystallization of Enantiomers. Chirality 2004, 16 (16), 499-508.

(31) Bruice, P. Y. How Specific Rotation Is Measured. In Organic Chemistry; Pearson, 2011; pp 208-210.

(32) Dalton, J. B.; Schmidt, C. L. A. The Solubilities of Certain Amino Acids and Related Compounds in Water, the Densities of Their Solutions at Twenty-Five Degrees, and the Calculated Heats of Solution and Partial Molal Volumes. II. J. Biol. Chem. 1935, 3 (109), 241-248.

(33) Temmel, E.; Gänsch, J.; Lorenz, H.; Seidel-Morgenstern, A. Measurement and Evaluation of the Crystallization Kinetics of 1 -Asparagine Monohydrate in the Ternary 1 -/ d -Asparagine/Water System. Cryst. Growth Des. 2018, 18 (12), 7504-7517.

(34) Cameli, F.; Xiouras, C.; Stefanidis, G. D. Intensified Deracemization via Rapid Microwave-Assisted Temperature Cycling. CrystEngComm 2018, 20 (21), 2897-2901. 
(35) Gogate, P. R. Intensification of Chemical Processing Applications Using Ultrasonic and Microwave Irradiations. Curr. Opin. Chem. Eng. 2017, 17, 9-14.

(36) Kacker, R.; Radoiu, M.; Kramer, H. J. M. Novel Design Integrating a Microwave Applicator into a Crystallizer for Rapid Temperature Cycling. A Direct Nucleation Control Study. Cryst. Growth Des. 2017, 17 (7), 3766-3774.

(37) Kacker, R.; Salvador, P. M.; Sturm, G. S. J.; Stefanidis, G. D.; Lakerveld, R.; Nagy, Z. K.; Kramer, H. J. M. Microwave Assisted Direct Nucleation Control for Batch Crystallization: Crystal Size Control with Reduced Batch Time. Cryst. Growth Des. 2016, 16 (1), 440-446. 